\title{
A prospective study of the accuracy of Doppler ultrasound in detecting carotid artery disease
}

\author{
MICHAEL J LAKEMAN, SUSAN B SHERRIFF, A ND \\ T ER R Y R P MAR T I N \\ From the Department of Medical Physics and Clinical Engineering, Royal Hallamshire Hospital, \\ Sheffield
}

SUMMARY Results are presented from a two year prospective study using a Doppler ultrasound technique for the detection of carotid disease. The patients studied presented with transient cerebral ischaemic attacks or small strokes in the carotid territory. No other form of patient selection was used. Results were compared with those from carotid and arch aortography. $86 \%$ of normal vessels and $78 \%$ of diseased vessels were correctly classified. It is concluded that this technique offers a safe and accurate screening procedure for the management of patients presenting with transient cerebral ischaemia or small strokes.

Management of a patient following an episode of transient cerebral ischaemia or small stroke in the carotid territory requires careful consideration as to whether carotid angiography should or should not be performed. As recently as $1979^{1}$ complications occurring in $12.2 \%$ of patients were reported and of these $5.2 \%$ were permanent. Reports in the literature ${ }^{2}$ show that directional Doppler ultrasound can provide a safe and harmless procedure for the demonstration of the presence of disease in the proximal carotid territory. We present the results from a two year prospective study of patients who had a transient ischaemic attack or small stroke in the carotid territory. The diagnostic accuracy of Doppler ultrasound, using criteria developed on a previous well selected group of patients ${ }^{3}$ is compared with per cutaneous carotid angiography and arch aortography.

\section{Patients}

A total of 122 Vessel segments were studied in patients referred by both physicians and surgeons at two general hospitals, in whom a diagnosis of a transient ischaemic attack or small stroke in the carotid territory had been made on clinical grounds. Patients

Address for reprint requests: Susan B Sherriff, Department of Medical Physics and Clinical Engineering, Royal Hallamshire Hospital, Sheffield S10 2JF, UK.

Accepted 7 April 1981 with complicating factors such as hypertension, diabetes, heart disease and migraine were included in the study. Patients were placed into one of five groups on the basis of angiographic findings as shown in table 1. All angiograms were reported by the same

Table 1 Classification of vessel segments according to angiograms

\begin{tabular}{|c|c|c|}
\hline Group & Description & Number \\
\hline $\begin{array}{l}\text { Normal } \\
\text { Minimal Atheroma }\end{array}$ & $\begin{array}{l}\text { Completely free from disease } \\
\text { Irregularity of vessel wall without } \\
\text { stenosis }\end{array}$ & $\begin{array}{r}50 \\
7\end{array}$ \\
\hline Less than $75 \%$ & $\begin{array}{l}\text { Definite stenosis no greater than } \\
75 \% \text { of luminal diameter }\end{array}$ & 35 \\
\hline $\begin{array}{l}\text { Greater than } 75 \% \\
\text { Occlusion }\end{array}$ & $\begin{array}{l}\text { Less than } 25 \% \text { of vessel lumen patent } \\
\text { Complete obstruction of vessel lumen }\end{array}$ & $\begin{array}{l}16 \\
14\end{array}$ \\
\hline Total & & 122 \\
\hline
\end{tabular}

person who had no prior knowledge of the patient's history or Doppler findings. An assessment of the degree of stenosis was made based on a measurable reduction in vessel lumen of the common or internal carotid arteries, from the projected vessel diameter at the point of maximum stenosis. In each case the best radiographic film was used. In six patients where film quality was poor or serious ambiguity existed, these were excluded from the study.

\section{Method}

Patients were placed in a supine position in a warm room. A period of 15 minutes was allowed after which 
brachial blood pressure was measured in each arm in the usual way with a sphygmomanometer. A $10 \mathrm{mHz}$ ultrasonic probe was placed below the level of the thyroid cartilage medial to the sternocleidomastoid muscle in the lower apex of the anatomical carotid triangle. The probe was inclinded towards the root of the neck so that the ultrasound beam was directed downwards. Doppler shifted signals were processed using a Parks $80610 \mathrm{mHz}$ Doppler in conjunction with a directional real time frequency analyser. ${ }^{4}$ The frequency-analysed Doppler signals were displayed on a storage oscilloscope. The probe was adjusted to give the clearest, most representative signal on the screen, free from artefacts caused by vessel wall movement and venous flow. The frequency analysed Doppler shifted signals were then recorded on a fibre-optic recorder at five $\mathrm{cm}$ per second. From these records the $\mathrm{A} / \mathrm{B}$ ratio as defined by Gosling 5 was calculated. This procedure was repeated with the probe placed in the upper medial angle of the orbit with the beam directed towards the supratrochlear artery as it emerges from the orbit. Great care was taken to ensure that the ultrasound beam was not directed towards sensitive structures lying within the eyeball.

The normal physiological direction of flow in the supratrochlear artery is towards the probe, reverse flow (flow away from the probe) being regarded as pathological. Branches of the external carotid artery were, singly or in combination, compressed and the effect on the supratrochlear signal was observed. In this way the sub-groups were defined as shown in table 2 and illustrated in figs 1 and 2 .

Table 2 Doppler test classification

\begin{tabular}{|c|c|}
\hline Group & Description \\
\hline Normal & $\begin{array}{l}\text { Sum of A/B ratios from carotid and } \\
\text { supratrochlear } 2 \cdot 3 \text { or more with forward } \\
\text { supratrochlear flow. }\end{array}$ \\
\hline Minimal atheroma & $\begin{array}{l}\text { Not defined by } \mathbf{A} / \mathbf{B} \text { ratio alone (see later } \\
\text { discussion). }\end{array}$ \\
\hline Less than $75 \%$ & $\begin{array}{l}\text { Sum of } A / B \text { ratios from carotid and } \\
\text { supratrochlear vessels less than } 2 \cdot 3 \text { with } \\
\text { forward flow in the supratrochlear being } \\
\text { enhanced by compression of branches of the } \\
\text { external carotid. }\end{array}$ \\
\hline Greater than $75 \%$ & $\begin{array}{l}\text { Reverse flow in the supratrochlear with } \\
\text { re-establishment of forward flow by } \\
\text { compression of branches of the external carotid }\end{array}$ \\
\hline Occlusion & $\begin{array}{l}\text { Reverse flow in the supratrochlear with no } \\
\text { forward flow by compression of branches of } \\
\text { the external carotid. }\end{array}$ \\
\hline
\end{tabular}

Carotid compression was occasionally performed where reverse flow was found and surgical intervention was anticipated. This was to ensure that reestablished forward flow in the greater than $75 \%$ groups was due to ipsilateral stenosis rather than ipsilateral occlusion with forward flow from other collaterals.

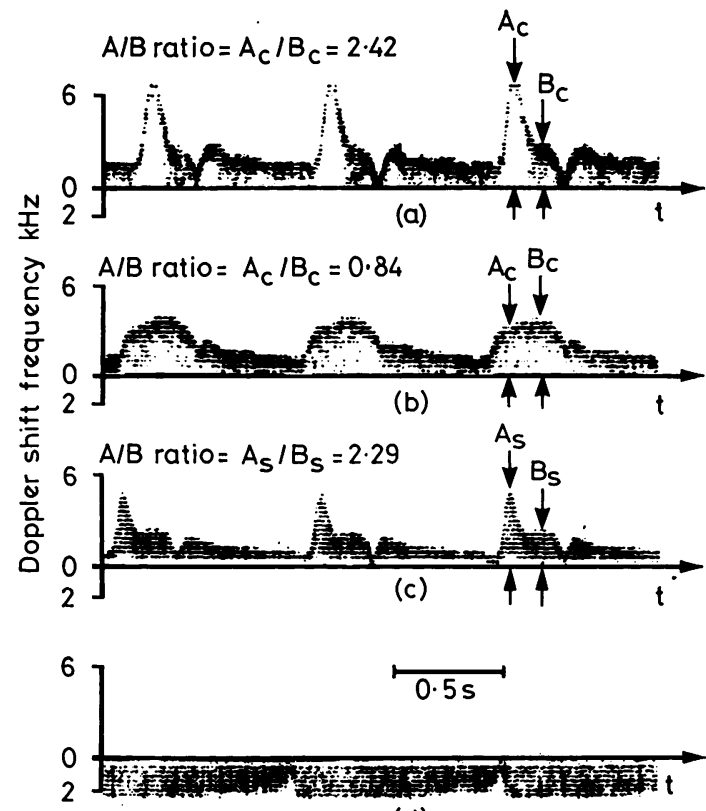

(d)

Fig 1 Frequency-analysed Doppler shifted signals recorded from: (a) common carotid artery in a patient with a normal bifurcation and extracranial vessels (normal group); (b) common carotid artery in a patient with carotid disease (less than $75 \%$ stenosis group); (c) the supratrochlear artery in a patient with a normal bifurcation and extracranial vessels (normal group); (d) the supratrochlear artery in a patient with severe occlusive disease of the internal carotid showing pathological reverse flow (greater than $75 \%$ stenosis group).

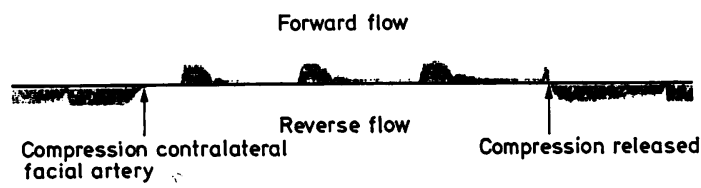

Fig 2 Pathological supratrochlear reverse flow with re-established forward flow on compression of an external carotid branch.

\section{Results}

The results are shown in table 3 and fig 3 . There were seven false positives in the normal group, $86 \%$ being correctly diagnosed. In three out of seven $(42 \%)$ other factors were present which could have accounted for the transient episode of cerebral ischaemia: one patient with recent myocardial infarction, one with aortic valve disease, and one with severe uncontrolled hypertension. 
Table 3 Results using Doppler classification test

\begin{tabular}{|c|c|c|c|c|c|}
\hline \multirow[t]{2}{*}{ Angiographic group } & \multicolumn{2}{|c|}{$\begin{array}{l}\text { Direction of supra- } \\
\text { trochlear flow }\end{array}$} & \multirow{2}{*}{$\begin{array}{l}\text { Doppler } \\
\text { classifica- } \\
\text { tion } \\
\text { A/B plus } \\
\text { direction } \\
\text { flow }\end{array}$} & \multirow{2}{*}{$\begin{array}{l}\% \text { Correct } \\
\text { Doppler } \\
\text { classifica- } \\
\text { tion }\end{array}$} & \multirow{2}{*}{ Total } \\
\hline & forward & reverse & & & \\
\hline Normal & 49 & 1 & 43 & 86 & 50 \\
\hline Minimal atheroma & 7 & 0 & 2 & 28 & 7 \\
\hline Less than $75 \%$ & 33 & 2 & 27 & 77 & 35 \\
\hline Greater than $75 \%$ & 3 & 13 & 13 & 77 & 16 \\
\hline Occlusion & 3 & 11 & 11 & 79 & 14 \\
\hline
\end{tabular}

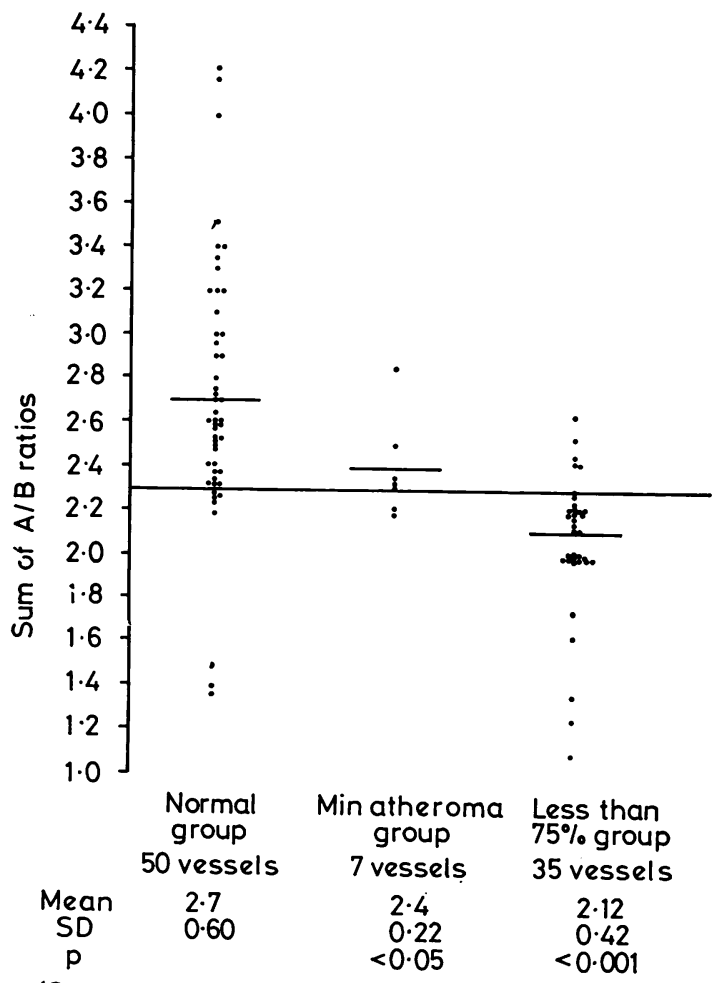

(Student $t$ test)

Fig 3 Sum of $A / B$ ratios calculated from the supratrochlear and common carotid arteries for each vessel segment. The mean and standard deviation for each group are shown.

In the remaining four, evidence of arterial disease elsewhere was found at angiography, for example, subclavian stenosis and middle cerebral occlusion.

In the less than $75 \%$ stenosis group, $77 \%$ were accurately assessed. For the group as a whole the mean degree of stenosis was $39.1 \%$ with a range of $14 \%$ to $74 \%$; of the eight incorrectly classified, two $(8.6 \%)$ were assessed as having more severe disease with supratrochlear reverse flow. Taken together, $85 \%$ were assessed correctly for the presence of carotid disease.

Only one patient in the greater than $75 \%$ group was found to have a normal Doppler result. In this case a small atheromatous plaque was found at operation, superimposed upon which was a large occlusive fresh clot. In two cases no reverse flow was shown but signals from both the carotids and supratrochlear vessels were very poor indicating the presence of significant occlusive disease. Overall $93.3 \%$ of diseased vessel segments were picked up with carotid Doppler.

In the occlusive group, three out of $14(21 \%)$ had ambiguous or forward supratrochlear flow. However, the orbit signals were so poor that the possibility of an occlusion was reported in all three cases. All diseased segments were therefore detected in this group.

\section{Discussion}

Transient cerebral ischaemia is a fairly common disorder with a yearly incidence of two per 1000 in 65 to 74 year-olds. ${ }^{6}$ Its importance lies in the fact that it is a forerunner of a permanent stroke. The consensus of opinion puts the chance of developing cerebral infarction within five years of a transient ischaemic attack as approximately $30 \%{ }^{7}$ At the time of presentation, disease in the common carotid vessels is usually considered as a possible cause for the transient ischaemic attack. An additional clinical problem is whether or not to investigate further a patient with an asymptomatic bruit. Hence a simple, safe, accurate and non-invasive method of investigating the common and internal carotid arteries is a substantial help since, as previously stated, arteriography is not without complication.

This study shows that the use of Doppler ultrasound goes a long way towards satisfying the above requirements and is in addition relatively inexpensive and also capable of producing the same results on separate occasions. Overall our results give a figure of $80 \%$ in predicting the presence or absence of disease in the proximal carotid territory. Figures in individual groups are much better and the overall figure is poor largely because we tried to include a group of people with minimal atheroma. We now feel that it is impossible to define accurately such a group using $\mathbf{A} / \mathbf{B}$ ratios 
alone, but a technique using principal components analysis may improve accuracy. ${ }^{8}$

This study unlike our previous trial ${ }^{3}$ was wholly unselective. We felt that the presence of aortic valve disease significantly affected signals obtained from the carotid vessel. In the presence of significant stenosis, marked diminution of signals was observed. However, where aortic incompetence was the predominant lesion, enhanced signals were recorded. We were particularly interested to find several patients with forward flow occlusion. We felt this probably occurred because a severe stenosis had been present for some time, allowing collateral development, particularly from the vertebral arteries. This was exemplified by a patien't who had had internal carotid ligation for bilateral intracerebral aneurysm. On the side more recently ligated reverse flow was still present in the supratrochlear artery. However, where ligation had been performed several years previously on the opposite side, forward flow was observed.

In conclusion this procedure, when compared with angiography and its inherent risks, provides a safe and accurate method of investigation. Although its accuracy is less than that of angiography, when the incidence of permanent complications is considered the reduction in diagnostic accuracy is more than compensated for by the absence of any iatrogenic complicating factors. We feel that this test provides a very satisfactory screening procedure for selection of patients for angiography.

\section{References}

1 Faught E, Trader SD, Hanna GR. Cerebral complications of angiography for transient ischaemia and stroke: prediction of risks. Neurology (Minneap) 1979; 29:4-15.

2 Baskett JJ, Beasley MG, Murphy GJ. Screening for carotid junction disease by spectral analysis of doppler signals. Cardiovasc Res 1977; 11: $147-55$.

3 Prichard DR, Martin TRP, Sherriff SB. Assessment of direction doppler ultrasound techniques in the diagnosis of carotid artery disease. $J$ Neurol Neurosurg Psychiatry 1979; 42:563-8.

4 Smallwood RH, Brown BH, Rodgers AW. A real time frequency analyser for ultrasonic dopple signals. J Med Engineer Tech 1977; 1: 221-2.

5 Gosling RG. Extraction of physiological information from spectrum analysed doppler shifted continuous wave ultrasound signals obtained noninvasively from the arterial system. In: Hill DW, Watson BW, eds. IEE Medical Electronics Monographs 13-22. London: Peter Peregrinus Ltd, 1976;33-125.

6 Whisnant JP. Epidemiology of stroke: emphasis on transient cerebral ischaemic attacks and hypertension. Stroke 1974; 5:68-74.

7 Toole JF, Janeway R, Choi K. Transient ischaemic attacks due to atherosclerosis. Arch Neurol 1975; 32:5-9.

8 Martin TRP, Barber DC, Sherriff SB. Objective feature extraction applied to the diagnosis of carotid artery disease using a doppler ultrasound technique. Clin Phys Physiolog Meas 1980; 1: 71-81. 